\title{
13th Austrian Chemistry Days: Poster Awards
}

\author{
Peter Gärtner
}

Published online: 19 May 2010

(C) Springer-Verlag 2010

In August 2009 the 13th Austrian Chemistry Days was organized in a scientific partnership between three neighboring EU countries as a joint meeting of the Czech, Slovak, and Austrian Chemical Societies at Vienna University of Technology. Chemists from these and other neighboring countries had the possibility to meet and to discuss science. In particular, young colleagues were invited to present their scientific results either as a lecture or a poster.

The International Union of Pure and Applied Chemistry (IUPAC) and the Austrian Chemical Society (GÖCH) each provided three prizes that were awarded for the six best poster presentations, and authors were invited to submit their contributions as full papers to Monatshefte für Chemie/Chemical Monthly. As a result of this we received the following papers which are presented at the end of this issue:

"Formation of the silylene-bridged complex $\mathrm{Fe}_{2}(\mathrm{CO})_{6}$ $\left(\mu_{2}-\mathrm{SiCl}_{2}\right)_{3}$ from cis- $\mathrm{Fe}(\mathrm{CO})_{4}\left(\mathrm{SiCl}_{3}\right)_{2}$-an experimental and computational study" by Van An Du, Gregor N. Stipicic, Maria Bendova, and Ulrich Schubert
"Organo-modified mesoporous silica for sorption of carbon dioxide" by Mária Badaničová and Vladimír Zeleňák

"Pickering emulsions stabilized by anatase nanoparticles" by Angelika Bachinger and Guido Kickelbick

"Characterization of micrometer sized magnetic optical sensor particles produced via spray-drying" by Klaus Koren, Günter Mistlberger, Daniel Aigner, Sergey M. Borisov, Armin Zankel, Peter Pölt, and Ingo Klimant

"Intramolecular Diels-Alder cyclization of biodihydroxylated benzoic acid derivatives towards novel heterocyclic scaffolds" by Thomas C. M. Fischer, Hannes G. Leisch, and Marko D. Mihovilovic

"Synthesis and anticancer activity of some 1,5-diaryl-3(3,4,5-trihydroxyphenyl)-1H-pyrazolo[4,3-e][1,2,4]triazines" by Tomáš Gucký, Eva Řezníčková, Petr Džubák, Marián Hajdúch, and Vladimír Kryštof

Enjoy reading,

Peter Gärtner

P. Gärtner ( $\square)$

Vienna, Austria

e-mail: peter.gaertner@tuwien.ac.at 